Int. J. Electrochem. Sci., 14 (2019) 6065 - 6076

International Journal of

ELECTROCHEMICAL

SCIENCE

WWW.electrochemsci.org

\title{
Electrochemical Rutin Sensor Based on Graphene Oxide and Functionalized Multiwall Carbon Nanotubes@nafion $0.1 \%$ Hybrid Nanocomposite modified glassy carbon electrode
}

\author{
Praveen Kumar $G^{l}$, Raja Nehru ${ }^{1}$, Shen-Ming Chen ${ }^{1 *}$, Bandar Mohsen Almunqedhi ${ }^{2}$, Tse-Wei Chen ${ }^{1,3}$, \\ Jun-Yu Wang ${ }^{1}$, Ming-Chin Y $u^{4, *}$, Noura M.Darwish ${ }^{5}$ \\ ${ }^{1}$ Department of Chemical Engineering and Biotechnology, National Taipei University of Technology, \\ Taipei 10608, Taiwan. \\ ${ }^{2}$ Department of Botany and Microbiology, College of Science, King Saud University, P.O. Box 2455, \\ Riyadh 11451, Saudi Arabia. \\ ${ }^{3}$ Research and Development Center for Smart Textile Technology, National Taipei University of \\ Technology, Taipei 106, Taiwan, ROC. \\ ${ }^{4}$ Department of Surgery, Chang Gung Memorial Hospital, Taoyuan 333, Taiwan (R.O.C) \\ ${ }^{5}$ Biochemistry Department, Ain Shams University, Dokki, Cairo 12311, Egypt. \\ *E-mail: smchen78@ms15.hinet.net(Shen-Ming Chen), mingchin2000@ gmail.com(Ming-Chin Yu)
}

doi: $10.20964 / 2019.07 .54$

Received: 5 March 2019 / Accepted: 16 April 2019 / Published: 10 June 2019

\begin{abstract}
A highly sensitive electrode based on graphene oxide and functionalized multiwall carbon nanotube hybrid composite as coated on glassy carbon electrode (GCE) for the electrochemical rutin sensor. The as-prepared GO/f-MWCNTs@ @ nafion composite was characterized by promising analysis such as field emission scanning electron microscopy (SEM), energy-dispersive X-ray spectroscopy (EDX), Fourier transform infrared spectroscopy (FT-IR), X-ray photoelectron spectroscopy (XPS), UV-Vis Diffusive reflectance spectroscopy (UV-DRS). The GO/f-MWCNTs@nafion/GCE hybrid nanocomposite revealed substantial electrocatalytic activity toward the rutin sensor. The GO/fMWCNTs@nafion/GCE electrode manifested voltammetric response over the concentration ranging of 0.02 to $39.69 \mu \mathrm{M}$ with a limit of detection (LOD) $0.004 \mathrm{nM}$, respectively. This analytical values suppressed the previously existing method for the electrochemical sensing of rutin. Additionally, the modified electrode proposed excellent stability, repeatability, and sensitivity.
\end{abstract}

Keywords: Flavonoid, Antioxidant, GO, $f$-MWCNTs, Hummer's method, and stability. 
(C) 2019 The Authors. Published by ESG (www.electrochemsci.org). This article is an open access article distributed under the terms and conditions of the Creative Commons Attribution license (http://creativecommons.org/licenses/by/4.0/). 